\title{
O DESENVOLVIMENTO DO APL DE CONFECÇÕES: UM ESTUDO SOCIOECONOMICO SOBRE O AGRESTE PERNAMBUCANO ${ }^{1}$
}

\author{
José Francisco Oliveira de Amorim \\ Professor da Faculdade de Economia, Administração e Contabilidade - FEAC/UFAL. Mestre em \\ Economia (ME/UFAL). \\ Maceió, AL, Brasil. \\ josefranciscoamorim@gmail.com \\ Rodolfo Vilar dos Prazeres \\ Economista (Unidade Santana do Ipanema/Campus do Sertão - UFAL) \\ Santana do Ipanema, AL, Brasil. \\ rodolfovillar@hotmail.com \\ Clelio dos Santos \\ Doutorando em Economia - PPGE/Universidade Federal da Bahia (UFBA) \\ Bahia, BA, Brasil. \\ cleliodosuab@bol.com.br
}

\begin{abstract}
Resumo - Este trabalhoanalisaos principais impactossocioeconômicosprovocados com a implantação do ArranjoProdutivo Local de Confecções do AgrestePernambucano, cenárioesse de grandeimportância para o processo de desenvolvimento da região. O estudo baseia-se no enfoque sobre os conceitos de Desenvolvimento Regional, Arranjo Produtivo Local como instrumento do desenvolvimento e as características do cenário nordestino na década de 60 comoprimórdio da mudança no setor econômico da região. Para isso, a metodologia utilizada consiste na coleta de informações e dados bibliográficos de estudos recentes de órgãos como IBGE, SEBRAE e DIEESE para formação do perfil socioeconômico do setor estudado. Os resultados demonstram um crescimento considerável da região pernambucana motivado pelo setor têxtil, alto índice de informalidade apresentado em decorrência do empreendedorismo familiar em vigor, assim como a exploração de alguns fatores que motivaram a região agreste de Pernambucano a abandonar a agricultura como fonte principal de obtenção de renda, promovendo a atividade confeccionista como principal atividade.
\end{abstract}

Palavras-chave: Arranjo Produtivo Local; Desenvolvimento Regional; Polo de confecções.

\section{THE DEVELOPMENT OF THE APL OF CONFECTIONS: A SOCIOECONOMIC STUDY ON AGRESTE PERNAMBUCANO}

\begin{abstract}
This work analyzes the main socio-economic impacts caused by the implementation of the Productive Arrangement Clothes Location Pernambuco's Agrest, this scenario of great importance to the development process of the region. The study is based on the focus on the concepts of Regional Development, Local Productive Arrangement as a development tool and the Northeastern landscape features in the 60 and beginnings of change in the economic sector in the region. For this, the methodology consists of collecting information and bibliographical data of recent studies of organs such as IBGE, SEBRAE and DIEESE for formation of the socioeconomic profile of the studied sector. The results show a considerable growth in Pernambuco region driven by the textile sector, high informality rate presented as a result of family entrepreneurship in force, as well as the exploitation of certain factors that motivated the rugged region of Pernambuco to abandon agriculture as the main source of getting income, promoting clothing manufacturer activity as main activity.
\end{abstract}

Keywords: Local Productive Arrangement; Regional Development; clothing Polo.

\footnotetext{
${ }^{1}$ Artigo apresentado no XII Congresso da Sociedade Brasileira de Economia, Administração e Sociologia Rural (SOBER NORDESTE, 2017), realizado em Juazeiro - Bahia.
} 


\section{INTRODUÇÃO}

Este trabalho tem como tema principal O Desenvolvimento do Arranjo Produtivo Local (APL) de Confecções: Um estudo socioeconômico sobre o Agreste Pernambucano. Sua escolha se deu principalmente pela importância que o setor de confecções têxtil vem promovendo, tanto a cidade de Caruaru e seus municípios vizinhos, como também a toda região do Agreste de Pernambuco. Importância essa que implica em mudanças causadoras de impactos no desenvolvimento socioeconômica da região.

A partir da década de 1950 o Brasil sofreu diversas mudanças em seu cenário, principalmente o industrial. O País sofria um tardio, mas importante, processo de desenvolvimento industrial, esse iniciado somente quando todas as possibilidades do modelo agroexportador se esgotaram. Com a posse de Juscelino Kubitschek no mesmo ano, daria inicio a jornada de crescimento do Brasil nesse setor e isso começaria destacando-se pela principal região em questão, o Nordeste.

A criação do Grupo de trabalho para o Desenvolvimento do Nordeste (GTND) foi um dos grandes planos favoráveis ao governo para que houvesse respostas nessas lutas de classe e apoio ao desenvolvimento da industrialização local (GREMAUD, 1996, p. 371).

Nesse cenário nordestino de crescimento entra o estado de Pernambuco, com suas características fortes de diversidade econômica, politica e social, possibilitando a realização de vários estudos para tentar incorporar as tendências politicas que o governo daquela época estava propondo. Com isso, é possível enxergar uma trajetória evolutiva do Arranjo Produtivo Local de confecções do agreste de Pernambuco, em especial os municípios de Caruaru, Toritama e Santa Cruz do Capibaribe, responsáveis pela grande parcela de receita gerada nesse setor para o estado. (SILVA, 2009)

Sendo assim os estudos dessa pesquisa serão focados na atividade que a indústria de confecções realizada no Agreste Pernambucano, assim também como o perfil socioeconômico da região em que essa atividade está situada.

Com base nessas intenções, busca-se responder ao seguinte questionamento: Quais os impactos socioeconômicos que o polo de confecções têxtil promove a região Agreste de Pernambuco? O objetivo principal deste trabalho consiste em:Analisar socioeconomicamente as principais características do APL de confecções do Agreste Pernambucano, com vista na atividade confeccionista, principalmente na forma pela qual o município tomou dessa atividade como um principio desenvolvimentista.

Para tanto ainda é possível estabelecer alguns objetivos específicos a serem estudados:

i. Caracterizar Desenvolvimento Local e APL;

ii. Caracterizar os municípios de Caruaru, Santa Cruz do Capibaribe e Toritama através de indicadores socioeconômicos; 


\section{METODOLOGIA}

O trabalho tem como planejado, através de levantamento bibliográfico e de disposição de dados, analisar os principais impactos econômicos verificados com a implantação do APL de confecções do Agreste de Pernambuco, principalmente nos municípios de Caruaru, Toritama e Santa Cruz do Capibaribe, demonstrando os reais motivos para que aregião pernambucana procurasse como forma alternativa, a indústria têxtil para desenvolver-se. Para que o estudo acontecesse foi necessário dividi-lo em três fases, que são: levantamento bibliográfico, coleta de informações referentes ao objeto de estudo e analise dos dados.

\section{AS VISÕES DA ECONOMIA QUANTO AO SENTIDO DO DESENVOLVIMENTO LOCAL}

$\mathrm{Na}$ atual economia mundial é interessante observar o fato de que as localidades, assim como os seus agentes sociais e suas devidas atividades desenvolvidas, estão num grande processo de readaptação e contínuo aprimoramento para que o sistema como um todo, continue no ciclo de produção e permaneça vivo conforme as mudanças e resistências que um setor, grupo, comunidade ou até mesmo que os territórios, sofrem conforme esse mundo vai evoluindo em seu processo de globalização cada vez mais acelerado. Por isso que a Ciência Econômica, que estuda a forma pela qual se empregam os recursos escassos a fim de produzir bens e serviços com o objetivo de satisfazer as necessidades humanas, utiliza da Teoria Econômica para conseguir interpretar o significado de diversos comportamentos dos principais fenômenos que ocorrem dentro de um processo de produção, crescimento ou reintegração de uma atividade econômica.

Schumpeter (1982, p.44) vai nos dizer que "[...] o mundo econômico é relativamenteautônomo, pois abrange uma parte tão grande da vida da nação e forma ou condiciona uma grande parte do restante [...]" ou seja, significa dizer que apesar do tamanho abrangente do mundo econômico e de toda a extensão de suas atividades desempenhadas, ainda se faz necessário de um determinado instrumento ou algum fator motivador capaz de promover esse processo autônomo do qual Schumpeter vai nos dizer. Afinal de contas, nada surge sem uma necessidade ou a falta de algo para que se possa promover essa mudança. Por isso que durante todo esse trabalho utilizaremos como apoio o conceito de Desenvolvimento Local, instrumento da economia um tanto recente que promove o entendimento dos fatores endógenos e exógenos que expliquem as necessidades da mudança de uma economia, tendo o fator endógeno como o mais importante para esse conceito. 


\section{O CONCEITO DE DESENVOLVIMENTO LOCAL}

Buarque em seu livro de Metodologia de Planejamento (2008, p.25) define como Desenvolvimento Local "o processo endógeno de mudança [do lugar], que leva ao dinamismo econômico e a melhoria da qualidade de vida da população em pequenas unidades territoriais e agrupamentos humanos". Somente com esse conceito apresentado pelo autor já é de conhecimento que para que se faça desenvolver uma localidade é preciso provocar uma mudança, um movimento de estratégia dos jogadores, uma melhoria ou qualquer alteração que promova um impacto necessário para a mudança repentina de um cenário que precisa de tal modificação. Porém, antes de chegarmos ao conceito mais elaborado de Desenvolvimento Local, é preciso explicar o que significa de fato essa mudança exógena ou endógena provocada por algum fator.

Bilale (2015) em seu estudo intitulado Desenvolvimento Comunitário Endógeno \& Desigualdade e Crescimento, nos dá exatamente os conceitos para fatores exógenos e endógenos como modificadores dos processos de desenvolvimento. Para o autor, a estratégia exógena se baseia nas ações e nos fatores externos ao local, em que a região fica dependente desses fatores e ações para que o desenvolvimento ocorra, por isso mesmo ela exige muita articulação dos autores locais embora sua participação seja fundamental para que esse modelo de desenvolvimento ocorra. Já quando se fala em Desenvolvimento endógeno refere-se ao desenvolvimento que surge a partir de dentro de um território local ou região. Pode ser delimitado geograficamente, politicamente ou culturalmente. São iniciativas que partem dos autores locais, esses que passam a ser os protagonistas do desenvolvimento da região. (BILALE, 2015, p.09).

O Desenvolvimento pode ocorrer de duas formas: a primeira forma é exógena, que ocorre através da intervenção de agentes externos a região, processo que ocorreu durante as ideias políticas de desenvolvimento implantadas durante a década de 70. E a segunda forma é a forma endógena, essa que se inicia exatamente a partir do local (BILALE, 2015, p. 10).

Para exemplificar melhor esse conceito de "mudança", utilizaremos como exemplo um empreendedor que trabalha na área de confecção de jeans. Todo processo de confecção das malhas na produção do jeans é a atividade desempenhada por esse sujeito para conseguir a sua produção. Sendo assim, qualquer atividade realizada de forma não convencional ao que o sujeito sempre emprega em sua produção será considerada como uma "mudança" nas atividades empenhadas. Utilizando do exemplo do produtor de jeans, ficará mais fácil explicar as mudanças exógenas e endógenas em sua atividade. Durante um determinado momento em que esse sujeito percebeu que sua produção estava caindo, ele decidiu procurar uma consultoria que o indicou a aplicar uma determinada mudança nas suas formas de produção, mudança essa que 
era tido como um modelo retirado de outro produtor de jeans localizado em outra região bastante longe da sua. Ao aplicar essa mudança indicada, nosso produtor percebeu que realmente ocorreu um aumento de produção em decorrência da mudança exógena, ou seja, que a implementação de uma nova mudança vinda de fora provocou mudanças em sua produção local. Porém, se nosso produtor prestasse mais atenção em sua produção e nos métodos utilizados para a confecção de jeans e através dessa observação constatasse que provocar uma pequena mudança, apenas com essa observação, sem a necessidade de fatores externos, ele conseguiria promover a mesma mudança em sua produção apenas com a análise interna de seus fatores, não recorrendo a fatores exógenos para isso.

Clóvis Cavalcante em seu artigo sobre Sustentabilidade da economia: paradigmas alternativos de realização econômica, destaca que "todo indivíduo deseja ser feliz, viver uma longa vida, alcançar a plena realização de si próprio, e somente o Desenvolvimento pode levar a tais objetivos" uma vez que melhoram as qualidades de vida (CAVALCANTI, 2009, p.163). Já quanto às ideias sobre mudanças sociais, dinamismo e exploração econômica, Armando Dias Mendes em seu ensaio intitulado Envolvimento e Desenvolvimento: Introdução à simpatia de todas as coisas nos diz que para que tais fundamentos ocorram é necessário um movimento de envolvimento, que segundo sua definição "é o que articula as ações do ser humano com o ambiente que o cerca [...] ambiente esse que precede o homem e é fruto das relações que ele entretece com o entorno de si mesmo" (MENDES, 2009, p. 54). Ou seja, que os movimentos dinâmicos provocados pela ação do homem, assim em parceria com as propostas de entidades governamentais, provocam o chamado "dinamismo econômico" que em consequência explora as potencialidades do ambiente em desenvolvimento, gerando então a viabilidade e a competitividade.

De uma forma sucinta, o Desenvolvimento Local promove uma mudança social e econômica através do processo de exploração dos fatores endógenos que promovam um certo tipo de mudança na localidade ou no objeto a ser analisado. Porém, é bom ressaltar que esse tipo de mudança não está apenas focado no sentido sociocultural, tecnológico ou politico, mas também na reorganização das outras dimensões da realidade. Buarque (2008, p.27) ainda ressalta que é necessária a utilização de três grandes pilares para a produção e aumento do Desenvolvimento Local:

A organização da sociedade, contribuindo para a formação de capital social local [...] combinada com a formação de espaços institucionais de negociação e gestão, agregação de valor na cadeia produtiva, com a articulação e o aumento da competitividade das atividades econômicas com vantagens locais, e a reestruturação e modernização do setor público local, como forma de descentralização das decisões e elevação de eficiência e eficácia da gestão pública local (2008, p.27). 
Em seu estudo intitulado Desenvolvimento sustentável: O desafio do século XXI, Veiga (2005) discute a confusão que muitos fazem ao se tratar do que é Desenvolvimento, confundindo o termo com crescimento econômico, uma vez que a base para se medir tal indicador é utilizando do Produto Interno Bruto per capita.

Celso Furtado (1974) escreve que a ideia de Desenvolvimento é um simples mito, uma vez que desvia a intenção da tarefa básica que é identificar as necessidades fundamentais da coletividade e das possibilidades que abrem ao homem o avanço da ciência em objetos abstratos como investimentos, exportações e crescimento. (FURTADO, 1974). Para ele:

[...] a ideia tem sido de grande utilidade para mobilizar os povos das periferias e leválos a aceitar enormes sacrifícios, para legitimar a destruição de formas de cultura arcaicas, para explicar e fazer compreender a necessidade de destruir o meio físico, para justificar formas de dependência que reforçam o caráter predatório do sistema produtivo (FURTADO, 1974, p.75-6)

Ainda segundo Furtado (1974, p.16) a literatura do conceito de Desenvolvimento econômico é um exemplo meridiano do papel diretor dos mitos nas ciências sociais, que deve ser socializado e universalizado nas ideias dos próximos estudiosos do tema, principalmente nos países que lideram a revolução industrial. Afinal de contas, os padrões de consumo da minoria da humanidade que atualmente vive nos países altamente industrializados poderão ser acessíveis às grandes massas de população em rápida expansão que formam a periferia.

Para complementar o pensamento de Buarque (2008) quanto à necessidade da intervenção da sociedade no processo de Desenvolvimento e no grau de organização que essa sociedade necessita para tal, Ignacy Sachs (2004, p.61) no seu estudo chamado Desenvolvimento includente, sustentável sustentado vai nos dizer que tal organização é necessária para o planejamento de todos os níveis territoriais de forma a reagrupar vários distritos unidos pela identidade cultural e pelos interesses em comum, características essas que serão utilizadas como do desenvolvimento. Para que isso ocorra, é necessária a criação de espaços que promovam o exercício da democracia direta, como foros e etc., que evoluam para a forma de conselhos consultivos e deliberativos, de forma a emponderar a sociedade no papel de desenvolver o futuro.

\section{O CONCEITO DE ARRANJO PRODUTIVO LOCAL E SEU PAPEL NO DESENVOLVIMENTO LOCAL}

Durante as décadas de 80 e 90, especificamente no comércio italiano, que o sucesso comercial das empresas instaladas nos chamados distritos industriais, inclusive no vale do silício na Califórnia, se tornou espantoso, uma vez que o termo Arranjo Produtivo Local - ou APL - se tornou popular, fato que ocorreu no Brasil nos últimos quinze anos, sendo reconhecidamente uma crítica à intervenção estatal. O termo APL foi aceito com foco no 
aproveitamento das externalidades do local defendido, produzindo entidades de direito privado. Porém, o seu conceito foi aceito definitivamente através de sua utilidade, já que era um termo atraente para se aplicar as regiões menos desenvolvidas, que durante essa época necessitavam de novos olhares para a aplicação de mudanças que modificassem os seus cenários econômicos. (SANTOS, DINIZ E BARBOSA, 2010, p.20)

Para definirmos o conceito de Arranjo Produtivo Local utilizaremos como apoio a definição dada por Cassiolato e Lastres em seu Glossário de Arranjos Produtivos Locais, que distingue APL como:

\begin{abstract}
A trajetória histórica de construção de identidades e de formação de vínculos territoriais (regiões e locais) a partir de uma base social, cultural, politica e econômica comum. São propícios a desenvolverem-se em ambientes favoráveis a interação, a cooperação e a confiança entre os atores. A ação de políticas tanto públicas como privadas pode contribuir para fomentar e estimular tais processos históricos de longo prazo. (2003, p. 4)
\end{abstract}

Em regiões periféricas que possuem mão de obra suficientemente qualificada, as grandes empresas podem se beneficiar duplamente pelos menores custos de mão de obra para manufatura e para engenharia e pesquisa [Universidades e etc], assim como em custos fiscais geralmente menores, desde que as condições de infraestrutura de transporte, energia e comunicação sejam minimamente adequadas (SANTOS, DINIZ E BARBOSA, 2010, p.42).

\title{
O ARRANJO PRODUTIVO LOCAL DO AGRESTE PERNAMBUCANO
}

Quando falamos em Agreste Pernambucano, estamos falando sobre os 71 municípios que compõem um quinto do estado de Pernambuco. Dentro dessa região estão inseridos quase 1,8 milhão de habitantes espalhados em seis microrregiões que trabalham, estudam e procuram de certa forma sobreviver às condições que são impostas no semiárido do segundo maior estado do Nordeste (IBGE, 2012).

Porém, para simplificar melhor os resultados dessa pesquisa, além de que, nem todos os 71 munícipios do agreste fazem parte da produção têxtil do estado, limitaremos nosso estudo apenas com os municípios dos quais é identificado a atividade têxtil em seus limites. Serão esses municípios que darão o peso de seus dados a pesquisa apresentada. Sendo assim, quando falamos nesse estudo em Agreste Pernambucano como participante da produção têxtil, estamos falando dos 20 municípios que se destacam e dão volume ao número apresentado no setor de confecções. 


\section{O TRIÂNGULO DAS CONFECÇÕES ${ }^{2}$}

Como demonstrado na ilustração anterior, os munícipios de Caruaru, Santa Cruz do Capibaribe e Toritama estão localizados há uma distância considerada uma da outra, mostrando então pela sua localização que ambas mantem uma relação de destaque sobre as demais, além é claro, de outros fatores que consideraremos mais a frente. Por esse motivo, destacaremos os três principais municípios pernambucanos que implicam sobre a importância do setor de confecções de produtos têxteis e seus derivados. Caruaru, Santa Cruz do Capibaribe e Toritama são considerados o "Triângulo das confecções" da região, exatamente por implicarem com um fluxo de produção considerado maior que em outras regiões e municípios menores do estado.

Figura01. Os três principais municípios de Produção Têxtil

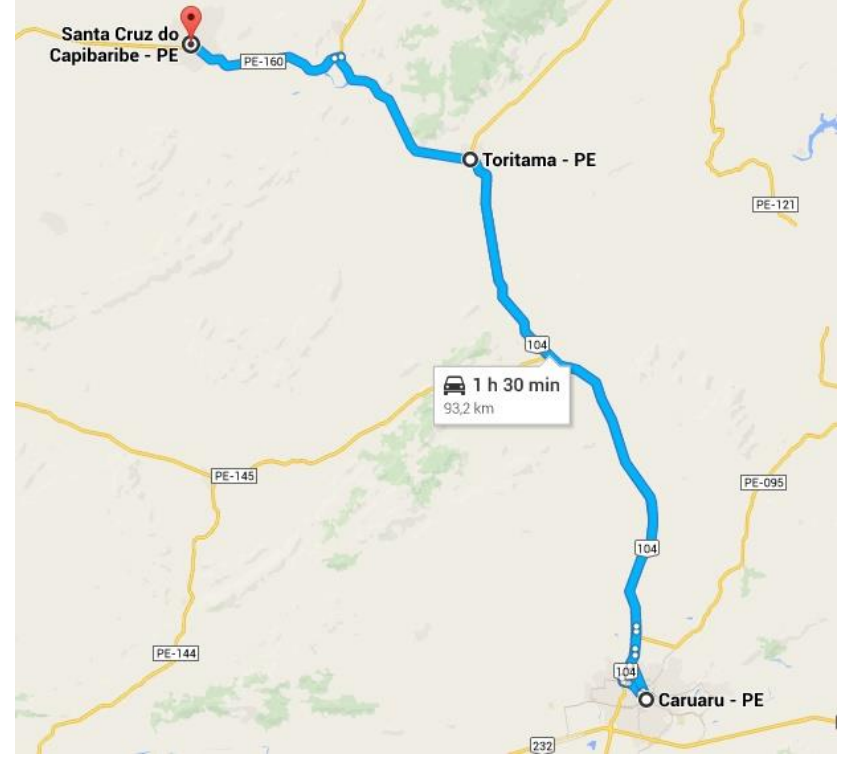

Fonte: Retirado do Google Maps, 2016.Adaptação do próprio autor.

Com esse contexto SILVA (2009, p.44) destaca em seu estudo que "na região do Agreste de Pernambuco a atividade confeccionista pode ser entendida como o processo final do complexo têxtil, sendo muito tradicional, e relativamente voltada para os mercados locais e regionais".

É importante também destacar que os três municípios são caracterizados pela especialização em determinadas mercadorias. Caruaru produz com maior eficácia peças em tecidos planos e malhas; Santa Cruz do Capibaribe produz grande quantidade de artigos em malha; já Toritama é destaque na fabricação de roupas em jeans, sendo conhecida como a Capital do Jeans. (SILVA, 2009).

\footnotetext{
${ }^{2}$ A maior parte dos dados apresentados foramretirados do site oficial do Governo de Pernambuco. 
Para entender melhor esse engajamento, principalmente a forma como se desenvolveu essa atividade, apresentaremos a seguir um perfil socioeconômico da região Agreste do estado Pernambucano.

\section{O PERFIL SOCIOECONÔMICO DA REGIÃO AGRESTE}

Com o passar dos anos, junto com a evolução das atividades do polo de confecções da região, foi possível observar algumas modificações populacionais e econômicas nos municípios pertencentes a região Agreste de Pernambuco. Essas mudanças foram cometidas por diversos fatores sociais, como a mudança na disponibilização de infraestrutura e serviços urbanos, porém a maior parte delas foi causada efetivamente pela evolução da produção e do crescimento das atividades do setor têxtil dos municípios. As tabelas 1 e 2 a seguir exemplificam com dados as verdadeiras e significativas mudanças ocasionados nesse processo de crescimento da região:

Tabela 01. Variação da população de Caruaru e seu Entorno - 2000/2010

\begin{tabular}{ccc}
\hline Munícipio & População 2010 & $\begin{array}{c}\text { Variação populacional entre } \\
\mathbf{2 0 0 0 / 2 0 1 0}(\mathbf{\%})\end{array}$ \\
\hline Agrestina & 22.679 & 13,2 \\
Brejo da Mãe de Deus & 45.180 & 18,6 \\
Caruaru & 314.912 & 24,6 \\
Cupira & 23.390 & 4,5 \\
Riacho das Almas & 19.162 & 5,6 \\
Santa Cruz do Capibaribe & 87.582 & 48,3 \\
Surubim & 58.515 & 16,3 \\
Taquaratinga do Norte & 24.903 & 26,0 \\
Toritama & 35.554 & 63,1 \\
Vertentes & 18.222 & 21,8 \\
Todos os municípios & $\mathbf{6 5 0 . 0 9 9}$ & $\mathbf{2 7 , 1}$ \\
- & - & - \\
Brasil & 190.756 .000 & 12,3 \\
Nordeste & 53.082 .000 & 11,2 \\
Pernambuco & 8.796 .000 & 11,1 \\
\hline
\end{tabular}

Fonte: IBGE, 2000 e 2010 - SEBRAE. Adaptação: Próprio autor.

É possível observar que durante o ano de 2010, segundo o ultimo censo realizado pelo IBGE, todos os municípios da amostra, nesse caso o município de Caruaru e seu entorno (aqui contendo 10 municípios), cresceram significativamente se comparados com o censo realizado em 2000. Observando com mais atenção, os municípios que mais se destacam quanto à esse crescimento são Caruaru (24,6\%), Santa Cruz do Capibaribe $(48,3 \%)$ e Toritama $(63,1 \%)$ sendo esse último o que mais cresceu durante os dez anos. Esse crescimento é significativo uma vez que, ainda segundo a tabela 7, a variação percentual total de crescimento da população desses municípios $(27,1 \%)$ ultrapassa a variação percentual apresentada pelo estado de Pernambuco $(11,1 \%)$, Nordeste $(11,2 \%)$ e 
Brasil (12,3\%). Até mesmo a variação percentual do estado se aproxima da variação percentual do Brasil como um todo, isso já motivado pelo crescimento desses munícipios. De um modo geral, entre 2000 e 2010 a população desses municípios variou no crescimento em torno de $27 \%$, isso motivado pelo grande aumento do êxodo de pessoas que migraram de pequenas cidades (ou mesmo da zona rural) para aquelas cidades em que enxergavam conseguirem uma melhor condição de vida social e econômica, isso já devido ao crescimento econômico que apresentavam.

Quando visualizamos os dados referentes ao Produto Interno Bruto (PIB) desses municípios, a situação é parecidíssima com os dados sobre população.

TABELA 02. Variação do PIB de Caruaru e seu entorno - 1996/2009

\begin{tabular}{|c|c|c|c|}
\hline Munícipio & PIB - 2009 (R\$) & $\begin{array}{c}\text { Variação Total do } \\
\text { PIB a preço constante } \\
\text { 2000/2010 }(\%)\end{array}$ & $\begin{array}{l}\text { Variação média } \\
\text { anual do PIB - } \\
1996 / 2009(\%)\end{array}$ \\
\hline Agrestina & 108.811 & 50,9 & 4,3 \\
\hline Brejo da Mãe de Deus & 163.271 & 48,2 & 6,7 \\
\hline Caruaru & 2.428 .599 & 49,2 & 5,7 \\
\hline Cupira & 93.631 & 29,4 & 5,4 \\
\hline Riacho das Almas & 91.226 & 67,6 & 3,8 \\
\hline $\begin{array}{c}\text { Santa Cruz do } \\
\text { Capibaribe }\end{array}$ & 400.885 & 63,9 & 8,6 \\
\hline Surubim & 269.852 & 45,1 & 5,6 \\
\hline Taquaratinga do Norte & 103.842 & 53,2 & 4,3 \\
\hline Toritama & 149.176 & 101,2 & 11,7 \\
\hline Vertentes & 66.013 & 57,4 & 6,5 \\
\hline Todos o municípios & 3.875 .206 & 56,1 & - \\
\hline- & - & - & \\
\hline Brasil & 3.239 .404 .000 & 36,2 & - \\
\hline Nordeste & 437.720 .000 & 47,9 & - \\
\hline Pernambuco & 78.428 .000 & 44,3 & - \\
\hline
\end{tabular}

Fonte: IBGE, 2000 e 2010 - SEBRAE

Adaptação: Próprio autor.

Quando observado o crescimento do PIB dentre esses municípios, ocorre o mesmo quanto ao crescimento populacional. Caruaru (49,2\%), Santa Cruz do Capibaribe $(63,9 \%)$ e Toritama $(101,2 \%)$ apresentam os maiores crescimentos durante o período entre 2000 a 2010, esse ultimo município crescendo muitíssimo acima da média anual. Esse fator também é crucial para o estudo, já que o Agreste Pernambucano ultrapassa da mesma forma as taxas estaduais $(36,2 \%)$, regionais $(47,9 \%)$ e nacionais (44,3\%) de crescimento do PIB. Em suma, entre 2000 e 2009 o PIB da região Agreste de Pernambuco expandiu 56\%. Isso significa um crescimento 2,2 vezes mais rápido que o Brasil e 2,4 vezes mais rápido que o Nordeste e Pernambuco.

Ainda segundo o IBGE (2010), a Incidência de Pobreza (pessoa com idade ativa com rendimento de até $1 \frac{1}{2}$ salário mínimo em 2010) os municípios que mais se destacam, ou seja, 
aqueles municípios que possuem uma população em que cada individuo tenha pelo menos meio salário mínimo, são: Santa Cruz do Capibaribe (em $7^{\circ}$ lugar), Caruaru (em $8^{\circ}$ lugar) e Toritama (em $11^{\circ}$ lugar). Já quanto ao Índice Firjan de Desenvolvimento Municipal (IFDM) de 2009, se destacam Caruaru (em $4^{\circ}$ lugar) e Santa Cruz do Capibaribe (em 15º lugar).

A dinâmica econômica dessas aglomerações empresariais tende a favorecer ao aumento de geração de emprego e renda, contribuindo para a diminuição das disparidades que possam existir. Com isso, a medida que o APL vai se desenvolvendo, as externalidades positivas provenientes dos mesmos vão se refletindo nos municípios mais próximos da região, efeito esse chamado de Transbordamento. (SILVA, p.54). Esse efeito explica o motivo para que alguns municípios acompanhem o crescimento de seus vizinhos mais favorecidos, uma vez que a tendência é que os municípios vizinhos "imitem" o estilo de desenvolvimento praticado por aqueles que já estão em desenvolvimento.Para complementar esse pensamento SILVA (2009) reforça dizendo:

"São todos municípios limítrofes, cujos habitantes ao perceberem a melhoria de renda dos moradores daquelas localidades que lograram em investir inicialmente na produção de artigos de vestuário, decidiram tentar auferir o mesmo resultado positivo dos seus vizinhos". (SILVA apud ANDRADE, 2008, p. 110).

\section{A CONFIGURAÇÃO DO APL DE CONFECÇÕES DO AGRESTE PERNAMBUCANO}

Segundo os versos da canção interpretada por Luiz Gonzaga, é possível encontrar de tudo que se venda na feira de Caruaru ${ }^{3}$. Apesar de ser um eufemismo relatando a extensão da feira local com sua cultura, tradição e pluralismo, a canção está certa quanto ao tamanho do popularismo da mesma, assim como das outras pertencentes aos demais municípios. Juntando as três principais cidades de distribuição têxtil do agreste, é possível enxergar a grande concentração do fluxo comercial do produto dentro do estado de Pernambuco.

A seguir será possível conhecer o volume de empresas atuantes no setor, a quantidade de mão de obra e como ela se classifica (nível de instrução, parentesco e renda), e a formalidade das Unidades em funcionamento. Todos esses motivos estarão interligados para a explicação do funcionamento do APL, configurando suas características na atuação dentro dos municípios participantes da amostra no Desenvolvimento do estado.

\footnotetext{
${ }^{3}$ A feira de Caruaru - Luiz Gonzaga (Composição de Onildo Almeida - 1973) 


\section{A FEIRA DA SULANCA}

Há um quarto de século foi possível notar o grande interesse de produtores e comerciantes ao redor das cidades de Caruaru, Santa Cruz do Capibaribe e Toritama. Quando perguntados sobre o destino comercial para compra de produtos para revenda, os comerciantes de outras cidades, e até mesmo os locais, respondem com um "Irei à feira da sulanca de tal cidade". A feira da Sulanca tem origem nos anos 1940, ainda quando Santa Cruz do Capibaribe era Vila e vários comerciantes vendiam restos de panos produzidos nas indústrias por preços baratos (SILVA, 2009). O termo popularizou e a expressão "Feira da Sulanca" tornou-se significado de fazer compras no polo de confecções do Agreste de Pernambuco, onde muitos aproveitam o comércio no grande centro de Caruaru ou simplesmente vão comprar na fonte, indo direto ao fabricante de vestuários em Toritama e Santa Cruz do Capibaribe. Porém vale lembrar que o termo "Feira da Sulanca", originário do tempo em que na região se comercializavam apenas retalhos de panos chamados "sulanca" na expressão popular, tornou-se depreciativo. Durante uma pesquisa realizada no ano de 2002 pela Fundação de Apoio ao Desenvolvimento da Universidade Federal de Pernambuco (FADE), o tradicional comércio e a fabricação de vestuários tornaram-se a chamar "Polo de confecções do Agreste Pernambucano", fazendo com que a terminologia antiga caísse em desuso e o novo termo passasse a soar mais formal para os inúmeros estudos que viriam a surgir daí por diante. Porém, ainda hoje várias pessoas ainda utilizam do termo "Feira da Sulanca" ou "Polo da Sulanca" para referir-se ao polo têxtil de Pernambuco. (SEBRAE, 2012).

O grande crescimento comercial dos produtos têxteis só se deu em 1980,quando junto com Caruaru e Santa Cruz do Capibaribe se junta Toritama, expandindo o processo produtivo de jeans (isso ocorrido com a instalação de lavanderias que auxiliaram no tingimento de peças). (ANDRADE, 2008, p. 116).

Em 1990 - período em que o Brasil durante sua conjuntura do momento abre seu comercio exteriormente - o APL do Agreste Pernambucano sofre alguns impactos econômicos, fazendo com que os confeccionistas necessitem unir-se para lutar contra as dificuldades da abertura do mercado brasileiro. (SILVA, 2009, p. 56).

Por essas razões é criada a Associação dos Confeccionistas de Santa Cruz do Capibaribe (ASCAP) e a Câmara de Dirigentes Lojistas (CDL) que propiciam a construção de estratégias competitivas. Sendo assim o Triangulo das confecções se une para encontrar melhorias no processo produtivo, trazendo melhorias de mão de obra, tecnologia e etc.. À medida que o mercado vai se estabilizando, Caruaru se transforma no maior centro de comercialização confeccionista, além de escoar boa parte da produção para outros estados, inclusive até outros países. 


\section{A CLASSIFICAÇÃO DAS UNIDADES PRODUTIVAS}

Segundo o SEBRAE (2012, p.25-6) classificou em seu estudo de análise, é possível encontrar três tipos de classificação para os empreendimentos como descritos a seguir:

- Unidade: é todo e qualquer conjunto de uma ou mais pessoas, com administração independente que se reúne de forma regular para (I) produzir confecções, (II) desempenhar funções que constituem o processo produtivo, (III) produzir componentes de peças. As unidades podem ser grandes ou pequenas, formais ou informais, de criação antiga ou recente;

- Empresa: é a unidade que produz confecções na forma de produtos finais. Algumas executam todos os processos de produção e outras subcontratam;

- Empreendimentos complementares: é unidade produtiva que desempenha tarefas que correspondem a etapas do processo de produção produtiva de confecções, como costuras ou produção de partes de uma peça.

Vale ressaltar que se uma Unidade diz que produz e vende um produto sem terceirizar, ela é considerada uma Empresa. Sendo assim, em todos os municípios participantes da amostra existem Unidades, Empresas e Empreendimentos complementares essas compostas por indústrias de grande porte, lojas de confecção de vestuário e roupa de cama, mesa e banho, pequenos ateliês de fabricação, boutiques, a feira pública e os polos de comercialização como o Shopping Moda Center.

\section{A ATIVIDADE NO APL DO AGRESTE PERNAMBUCANO}

Para respondermos ao problema levantado nesse estudo, os próximos tópicos analisarão como se configura a atividade no setor de produção confeccionista, mostrando então a quantidade de Unidades em funcionamento assim como sua formalidade e informalidade, a quantidade e classificação da mão de obra e como tais fatores implicam na atividade desempenhada no setor, principalmente na relação entre a população empregada nesse tipo de atividade e a importância do polo para o Agreste Pernambucano.

Durante o ano de 2012 foi registrado o maior aumento do número de unidades produtivas de confecção no Agreste Pernambucano. Esse aumento deu-se pela descoberta do setor têxtil como sendo o maior potencial de crescimento da região, uma vez que possibilita outras formas de captar os ganhos da economia que não seja as atividades agropecuárias ou atividades com o setor de serviços. A tabela a seguir comprava esse crescimento, dando destaque não somente para as dez cidades da amostra, mas principalmente as três principais: Caruaru com 24,1\%, Santa Cruz do Capibaribe com $38,1 \%$ e Toritama com $15,0 \%$ do total de unidades da região em atividade. 
Tabela 03. Quantidade estimada de unidades produtivas de confecção nos dez municípios do Agreste Pernambucano - 2012.

\begin{tabular}{ccccc}
\hline Municípios & $\begin{array}{c}\text { Número de } \\
\text { unidades }\end{array}$ & \% do total & $\begin{array}{c}\text { Quantidade de } \\
\text { empresas }\end{array}$ & $\begin{array}{c}\text { Quantidade de } \\
\text { empreendimentos } \\
\text { complementares }\end{array}$ \\
\hline Agrestina & 299 & 1,6 & 129 & 170 \\
$\begin{array}{c}\text { Brejo da Mãe de } \\
\text { Deus }\end{array}$ & 1.396 & 7,4 & 1.156 & 240 \\
Caruaru & 4.530 & 24,1 & 1.313 & 3.217 \\
$\quad$ Cupira & 135 & 0,7 & 80 & 55 \\
Riacho das Almas & 415 & 2,2 & 124 & 291 \\
Santa Cruz do & 7.169 & 38,1 & 5.722 & 1.497 \\
Capibaribe & & & & 163 \\
Surubim & 454 & 2,4 & 291 & 364 \\
Taquaratinga do & 1.185 & 6,3 & 821 & 1.856 \\
$\quad$ Norte & & & & 255 \\
Toritama & 2.818 & 15,0 & 962 & 8.060 \\
Vertentes & 401 & 2,1 & 146 & \\
Total da amostra & 18.803 & 100,0 & 10.744 & \\
\hline
\end{tabular}

Fonte: Pesquisa Polo de Confecções de Pernambuco - SEBRAE (2012).

Adaptação: Próprio autor.

Dentre as três cidades do triângulo das confecções, a que mais teve variação quanto ao seu crescimento de Unidades produtivas entre 2002 e 2012 foi Caruaru (90,34\%), seguida de Toritama (28,32\%). Caruaru foi o município com maior crescimento de Unidades Produtivas devido ao elevado número de empresas comerciais que foram inauguradas nos últimos anos, além de ser o centro de comercialização e realizar uma boa parte do processo produtivo final da confecção. No município de Santa Cruz do Capibaribe ocorre um fato específico sobre a variação do PIB nos municípios citados, a mesma apresenta um crescimento de 63,9\% enquanto que na Tabela 10 (a seguir), é apresentado um declínio no número de Unidades produtivas criadas recentemente. Segundo o SEBRAE:

\footnotetext{
A única explicação para o declínio do número de unidades produtivas em Santa Cruz do Capibaribe é que tenha havido um processo de concentração do setor produtivo, ou seja, que as unidades produtivas se tenham tornado maiores, de modo que um número menor delas fosse capaz de gerar uma produção maior. (SEBRAE, 2012, p.35). ${ }^{4}$
}

Tabela 04. Quantidade estimada de variação de unidades produtivas entre 2002 e 2012 (Apenas os municípios de Caruaru S. Cruz do Capibaribe e Toritama)

\begin{tabular}{cccc}
\hline Municípios & $\mathbf{2 0 0 2}$ & $\mathbf{2 0 1 2}$ & $\begin{array}{c}\text { Variação 2002/2012 } \\
(\mathbf{\%})\end{array}$ \\
\hline Caruaru & 2.380 & 4.530 & 90,34 \\
$\begin{array}{c}\text { Santa Cruz do } \\
\text { Capibaribe }\end{array}$ & 7.565 & 7.169 & $-5,23$ \\
$\quad$ Toritama & & & \\
$\quad$ Total & 2.196 & 2.818 & 28,32 \\
\hline
\end{tabular}

Fonte: Pesquisa Polo de Confecções de Pernambuco - SEBRAE (2012).

Adaptação: Próprio autor.

\footnotetext{
${ }^{4}$ Essa explicação é necessária para explicar o motivo de dados tão contraditórios. Segundo a pesquisa realizada pelo SEBRAE, o motivo mais óbvio para esse acontecimento é a mudança da forma metodológica de aplicação da pesquisa que foi realizada entre 2000 e 2010, sendo nesse ultimo ano reformulada. A mudança na forma metodológica não afeta os resultados do estudo.
} 
Quando analisado os resultados quanto à formalidade dessas Unidades Produtivas, os números revelam uma informação bastante relevante (Tabela 12) que explicará algumas outras informações mais adiante. Segundo dados da RAIS (2012), todos os municípios da amostra apresentam maior número de Unidades informais, ou seja, que não são registradas no Cadastro Nacional de pessoas Jurídicas, não possuindo então o CNPJ.

Também como mostra a tabela a seguir, o maior índice de Unidades Informais está localizada na categoria dos Empreendimentos Complementares com 93,2\% seguido do número maior de Unidades do tipo Empresa com 66,4 \% sendo formais.

Tabela 06. Quantidade de pessoas ocupadas nas Unidades produtivas e quantidade da população em idade ativa nos municípios da amostra -2012

\begin{tabular}{cccc}
\hline Município & $\begin{array}{c}\text { Total de pessoas } \\
\text { ocupadas na confecção }\end{array}$ & $\begin{array}{c}\text { População em idade } \\
\text { ativa }\end{array}$ & $\begin{array}{c}\text { Relação percentual } \\
\text { das pessoas } \\
\text { ocupadas na } \\
\text { confecção e da } \\
\text { população em } \\
\text { idade ativa (\%) }\end{array}$ \\
\hline Agrestina & & & 7,4 \\
Brejo da Mãe de Deus & 1.402 & 18.959 & 20,6 \\
Caruaru & 7.580 & 36.864 & 9,4 \\
Cupira & 24.963 & 264.345 & 6,5 \\
Riacho das Almas & 1.286 & 19.666 & 16,2 \\
Santa Cruz do & 2.629 & 16.185 & 53,8 \\
Capibaribe & 38.973 & 72.459 & 6,5 \\
Surubim & & & 29,3 \\
Taquaratinga do Norte & 3.184 & 49.291 & 61,4 \\
Toritama & 6.972 & 20.721 & 22,1 \\
Vertentes & 17.750 & 28.908 & 19,8 \\
Total & 3.338 & 15.117 & 542.521 \\
\hline
\end{tabular}

Fonte: Pesquisa Polo de Confecções de Pernambuco - SEBRAE (2012).

Adaptação: Próprio autor.

Quando destacado da pesquisa a quantidade de familiares trabalhando nas unidades produtivas, ou seja, quantas pessoas que são parentes que trabalham na mesma empresa em comum, o número é considerado importante.

\section{CONSIDERAÇÕES FINAIS}

A implantação de Arranjos Produtivos Locais garante melhorias e alternativas diferentes de desenvolvimento para uma região carente do processo de crescimento econômico, por qualquer via que seja. É a utilização do APL como ferramenta de desenvolvimento que provoca a criação e ampliação do estudo nessa área como maneira, exógeno e endógena, de melhoria nas tomadas de decisão entre os agentes de um sistema econômico que procura desenvolver-se. 
Esse processo alternativo de crescimento através da implantação do APL ficou bastante claro e evidente quanto ao seu sucesso na região Agreste de Pernambuco e seu Polo de confecções Têxtil. A mudança desse setor, através de um processo histórico-natural, deu-se com a evidência do fracasso apresentado desde a década de 1960 com a proposta de desenvolver a região Nordeste através de planos governamentais que apenas provocaram transferências massivas de recursos e infraestruturas, e que fracassaram quanto ao alvo do plano que era desenvolver a região carente de chuvas, fortalecer a agricultura e fazer crescer os números da economia. Foi com o indicio da cultura do algodão - produto abundante na região - que a economia têxtil deu seu pontapé inicial a partir da década de 1970 e a região conseguiu sair do cenário de subdesenvolvimento e, aproveitando a crise hidráulica e o fracasso da agricultura, usou das indústrias de confecção para estabelecer-se como a região que mais cresce como polo produtor de vestuário do Nordeste.

A região Agreste, principalmente Caruaru, Santa Cruz do Capibaribe e Toritama, transformou-se no centro de produção e comercialização de confecções do estado, tornando-se referência em todo Nordeste e até mesmo o Brasil. A produção local motivou o crescimento da mão-de-obra, do número de unidades produtivas e até mesmo do pensamento empreendedor, o que mesmo com o alto grau de informalidade dos negócios, transformará grande porcentagem dessas unidades em futuros empreendimentos formais e até incentivar a criação de cursos de capacitação, uma vez que grandes órgãos públicos transformam o Polo de confecções em alvo de pesquisas e olhares de interesse.

É bem claro que essa informalidade é o fator principal que faz da produção têxtil um negócio vantajoso, já que boa parte das unidades produtivas são consideradas como Empreendimentos Complementares, realizando atividades terceirizadas e com menor custo (motivado pela não formalização). Outro fator é a criação dessas Unidades produtivas através de relações familiares, explicando o alto grau de aplicação de conceitos de empreendedorismo. Um ponto negativo é o preocupante baixo grau de escolaridade dos indivíduos que trabalham nesse tipo de atividade, já que a maioria nem sequer concluiu o ensino fundamental completo. A explicação para esse fator, segundo a literatura, é a não exigência de requisitos escolares nos processos mais básicos da produção têxtil, ficando os indivíduos com alto grau de escolaridade apenas ocupados nos níveis organizacionais ou de criação.

Sendo assim, as Unidades produtivas do Agreste Pernambucano oferecem título de instrumento de desenvolvimento para a região, sendo necessário à criação de incentivos e planos governamentais que foquem no principio de tornar a região Nordeste uma das pioneiras na Indústria de Confecção, ampliando o comércio local e colocando as confecções na pauta exportadora de produtos de qualidade para outros estado e até mesmo outros países. 


\section{REFERÊNCIAS}

ABIT. Disponível em <http://www.abit.org.br>. Acessado em 23/10/2014

Associação Brasileira da Indústria Têxtil e de confecções (ABIT). Cartilha da Indústria têxtil e confecção Brasileira: Cenários, Desafios, Perspectivas, Demandas.

BARROS, Aidel Jesus Paes; LEHFELD, Neide Aparecida de Souza. Fundamentos de metodologia Cientifica.Brasil: Makron, 3.ed. 2007.

BARROS, IZABELLE SOUZA, O cenário do polo de confecções do agreste de PernambucoSENAC, Pernambuco, 2009.

BEZERRA, FRANCISCO DINIZ. Análise retrospectiva e prospectiva do setor têxtil no Brasil e Nordeste. Ceará, 2014

BILALE, Aderito Francisco. Desenvolvimento comunitário endógeno \& Desigualdade e crescimento.Moçambique: Universidade pedagógica de Moçambique, 2015.

BORGES G.M., ANDRADE A.M. NO desenvolvimento local de Caruaru via indústria de confecção: Uma alternativa possível? Interfaces, Caruaru, 2006.

BRASIL. Lei complementar n. 125, de 03 de Janeiro de 2007. Institui na forma do art. 43 da Constituição federal a Superintendência do Desenvolvimento do Nordeste. LEX: Presidência da República, Casa Civil. Brasília, Decreto n. 6.219, jan. 2007.

BUARQUE,SÉRGIO C.. Construindo o desenvolvimento local e sustentável: Metodologia de planejamento. Rio de Janeiro: Garamond, 2008. $4^{\mathrm{a}} \mathrm{ed}$.

CAVALCANTI, Clóvis (Org.). Desenvolvimento e Natureza: Estudos para uma sociedade sustentável.5.ed. São Paulo: Cortez; Recife,PE: Fundação Joaquim Nabuco, 2009.

DINIZ, Clécio Campolina; BASQUES, Maria Fernanda Diamante. A industrialização Nordestina recente e suas perspectivas. Fortaleza: Banco do Nordeste do Brasil, 2004.

FURTADO, Celso. O mito do desenvolvimento econômico. Rio de Janeiro: Paz e Terra, 1974.

FURTADO, Celso. O Brasil Pós-milagre.Rio de Janeiro: Paz e Terra, 1981.

Geografia do estado de Pernambuco. Governo estadual de Pernambuco. Disponível em $<$ http://www.pe.gov.br/conheca/geografia/>. Acessado em 31/05/2016.

GREMAUD, Amaury Patrick. Economia Brasileira Contemporânea.7.ed. São Paulo: Atlas, 2011.

IBGE. Disponível em <http://www.ibge.gov.br>. Acessado em 06/01/2015

IEME. Disponível em <http://www.iemi.com.br>. Acessado em 25/05/2016.

LASTRES, Helena M.M.; CASSIOLATO, José E. Glossário de Arranjos produtivos Locais e InovativosLocais. Rio de Janeiro: SEBRAE, 2003.

LUCENA,CARLOS AUGUSTO ARAÚJO et al. A indústria de confecções em Pernambuco: Impacto e oportunidade em um cenário pós-ATC (Acordo sobre têxteis e confecções) 2006.

Moda Center Santa Cruz. Disponível em <http://goo.gl/5zgCZk> Acessado em 25/05/2016.

OLIVEIRA, Francisco de. Elegia para uma Re(li)gião: SUDENE, Nordeste. Planejamento e Conflito de classes. Rio de Janeiro: Paz e Terra, 1977.

Portal G1. Agreste de Pernambuco vive a pior seca dos últimos anos.2012. Disponível em <http://goo.gl/P512xf>. Acessado em 03/06/2016.

Portal G1. Seca provoca redução na produção de leite no Agreste de Pernambuco. Disponível em <http://goo.gl/fD3aVW>. Acessado em 03/06/2016.

PROCHNIK, VICTOR. Estudo da competitividade de cadeias integradas no Brasil: Impactos das zonas de livre comércio. Campinas, 2012

RAIS. Disponível em <http://www.rais.gov.br>. Acessado em 25/05/2016.

Relatório de Diagnóstico DIEESE, Relatório final Diagnóstico do setor têxtil de confecções de Caruaru e região. 2010

SANTOS, Gustavo Antônio Galvão dos; DINIZ, Eduardo José; BARBOSA, Eduardo Kaplan. Arranjos Produtivos Locais e Desenvolvimento.BNDES: 2010.

SACHS, Ignacy. Desenvolvimento includente, sustentável sustentado. Rio de Janeiro: Garamond, 2008.

REVISTA ECONOMIA POLÍTICA DO DESENVOLVIMENTO $\quad$ Maceió - AL $\quad$ V.3 N.5. $\quad$ DEZEMBRO/2016 P.39-56 Página-55 
SCHUMPETER, Joseph Alois. Teoria do desenvolvimento econômico: uma investigação sobre lucros, capital, juro e o ciclo econômico. São Paulo: Abril Cultural, 1982.

SEBRAE. Disponível em <http:// http://www.sebrae.com.br/sites/PortalSebrae〉. Acessado em 25/05/2016.

SILVA, TAMYRES VERIDIANA DA, Arranjo Produtivo Local de Confecções: O caso do Município de Caruaru, Pernambuco, 2009.

SOUZA, NALI DE JESUS DE. Desenvolvimento Econômico. São Paulo, 2012. $6^{\text {a }}$ ed. revisada

SUDENE.Desempenho Econômico da Região Nordeste do Brasil: 1960-9.Brasília: SUDENE, 1999.

SUDENE. Disponível em <http://sudene.gov.br>. Acessado em 05/05/2016.

VEIGA, José Eli da. Desenvolvimento sustentável: O desafio do século XX. Rio de Janeiro: Garamond, 2010. 